\title{
Canales de YouTube para amar las matemáticas
}

Rodolfo Rafael Medina Ramírez

$\mathrm{S}$ é que mi afirmación es pretenciosa, pero también de eso va la docencia: de consolidar nuestras pasiones por asuntos superiores para poder comunicarlas a nuestros estudiantes. A mí me encantan las matemáticas y permanentemente busco medios para acercarlas a mis estudiantes. Hay libros extraordinarios, pero a nuestros estudiantes les asusta el tema y cualquier documento de más de cinco cuartillas los desanima, de ahí que he encontrado una colección de canales de YouTube que pueden ser útiles en esta empresa pantagruélica. El contenido que promueven estos canales es adecuado para estudiantes de secundaria hasta los de educación superior, particularmente en la primera mitad de pregrado, aunque en lo personal los he promovido entre estudiantes de maestría. En los modelos educativos de hoy, que buscan promover el aprendizaje independiente, estos canales se convierten en recursos relevantes en la búsqueda de esa competencia transversal.

Buscando un tutorial de Javascript ${ }^{1}$ me encontré con el sitio de un profesor de Australia que se hace llamar Magic Monk, en ese canal hay tutoriales de matemáticas y de varios asuntos de tecnología. Son videos cortos (de no más de 20 minutos) y diseñados para poner manos a la obra. Estos tutoriales están en inglés, por lo que podría ser un gran inconveniente para quienes no dominen el idioma, sin embargo, ofrecen una pronunciación clara y se puede comprender con facilidad.

Hay otro canal que me encanta y se llama Numberphile, algo así como 'amor por los números', que ofrece videos que duran en promedio unos 10 minutos y abordan distintos temas como: el experimento de Buffon, ${ }^{2}$ el número $e$, los siete puentes, la medalla Fields, entre otros. Participan varios matemáticos, entre ellos Cédric Villani, el

1 Lenguaje de programación para desarrollar páginas interactivas de Internet.

2 Experimento del siglo XVIII que se considera la base de la simulación Monte Carlo que sirve para obtener una aproximación del número $\pi$. hombre araña de las matemáticas. Al igual que el canal previo es en inglés, pero muy ilustrativo y divertido.

Hay un canal en español: Derivando, conducido por Eduardo Sáenz de Cabezón. El conductor es doctor por la Universidad de La Rioja con una tesis sobre álgebra computacional. En su canal, a semejanza del anterior, aborda distintos tópicos matemáticos: números complejos, probabilidades, derivadas, crecimiento exponencial, fractales, las mujeres matemáticas más importantes de la historia, por mencionar unos cuantos. Sus videos son muy breves, rara vez exceden los cuatro minutos, (en general se apega a un formato de tres minutos) combina los conceptos con el buen humor y lo logra de manera agradable. Sus videos pueden ayudar a introducir a los aprendices a un estudio más formal de los temas que aborda este canal de una manera divertida.

A diferencia de otros canales, con un enfoque de entretenimiento estrictamente, estos videos tienen en promedio unas doscientas mil reproduc- 
ciones, pero los más populares de Numberphile tienen varios millones de reproducciones. Los de Derivando (Imagen 1), de momento, tienen poco más de cien mil reproducciones cada uno, pues es un canal relativamente reciente.

En lo personal, no soy aficionado a ver videos, pero entre los jóvenes que pueblan nuestras aulas es un medio potente de comunicación; si diseñamos una estrategia en la que se combinen el consultar un video con un experimento y una posterior redacción de conclusiones, podemos sacar partido de un recurso que es prácticamente ubicuo $\mathrm{y}$ de costo reducido en su consumo.

Sé que debe haber más canales, conozco otros de ciencia que le encantan a mi hija adolescente, pero en esta entrega quise enfocarme a las matemáticas. Espero que los puedan disfrutar y que amplíen su videoteca de opciones.

\section{Fuentes de consulta}

Haran, B. (06 de febrero de 2017). Numberphile. Obtenido de YouTube Channel: https:// www.youtube.com/user/numberphile/featured

Magic Monk. (06 de febrero de 2017). Magic Monk Tutorials. Obtenido de YouTube channel: https://www.youtube.com/user/bulletproofmonk32/about

Sáenz de Cabezón, E. (06 de febrero de 2017). Derivando. Obtenido de YouTube Channel: https://www.youtube.com/channel/UCHZ8ya93m7_RD02WsCSZYA

\section{c|} - Es seguro hittps/wwww.youtube.com/channe//VCH-28ya93m7_RDO2WsCSzYA

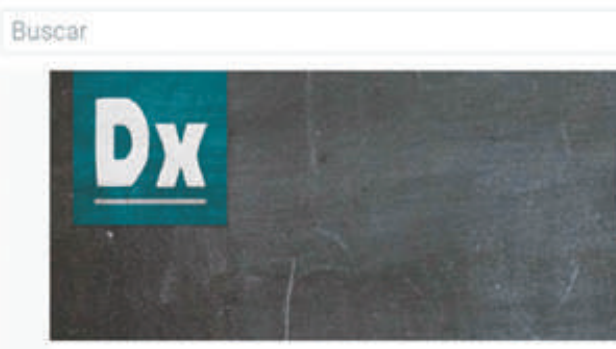

Derivando

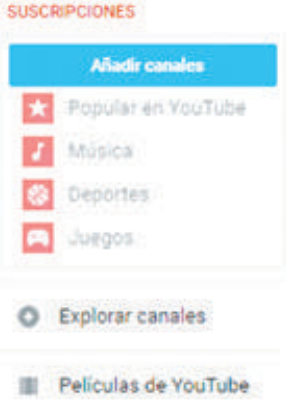

Inicio Videos Listas de reproducción Canales Comentarios Màs información

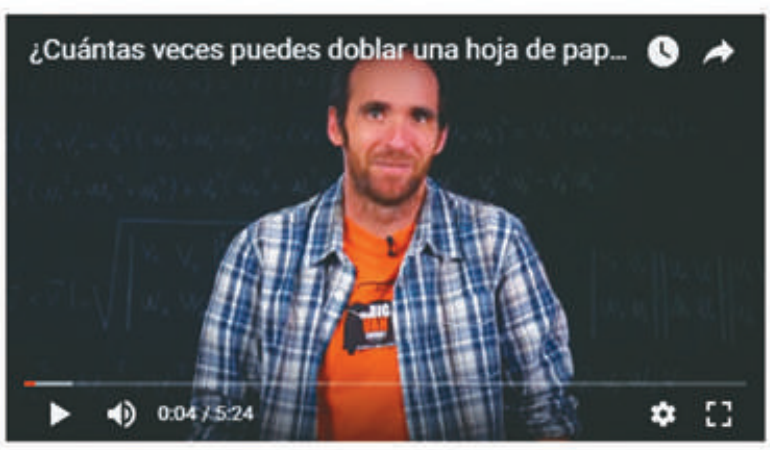

¿Cuántas veces puedes doblar una hoja de papel? 322.717 visualizaciones Hace 2 arhos

cCuántas veces se puede doblar una hoja de papel po la mitad? Te damos la solución iSuscribete a Derivandol

Sigue a Eduardo Saenz de Cabezón hittp:/itwitter com/edusadec
Canales destacados

unif

maztelalista Suscribirse

? Que significa Suscribirse

(88) Date un Voltio Suscribirse

Canales relacionados

QuantumFracture 0 Suseribirse

Imagen 1. Captura de pantalla del canal de You Tube "Derivando". 